\title{
Calcium and neurogenesis in Alzheimer's disease
}

\author{
Jun Ming Wang* and Chenyou Sun
}

Department of Pathology, University of Mississippi Medical Center, Jackson, MS, USA

Edited by:

Xiao-Ming Ou, University of Mississippi

Medical Center, USA

Reviewed by:

Jason B. Wu, University of Southern

California, USA

Govindan Dayanithi, Institute of

Experimental Medicine of the

Academy of Sciences of the Czech

Republic, Czech Republic

${ }^{*}$ Correspondence:

Jun Ming Wang, Department of

Pathology, University of Mississippi

Medical Center, 2500 N State Street,

Jackson, MS 39216, USA

e-mail: jwang@umc.edu
It was evidenced that impairment of calcium homeostasis is a potential mechanism in the development of Alzheimer's disease (AD). It remains, however, unclear how the calcium signaling are associated with in AD progression. Here we review recent studies to discuss the relationship among the signaling of intracellular calcium concentration, neurogenic activity, and AD progression. Analyzing these findings may provide new ideas to improve the neurogenic status in pathological processes in the aging brain.

Keywords: calcium homeostasis, alzheimer's disease, allopregnanolone, neurogenesis

\section{INTRODUCTION}

Alzheimer's disease (AD) is the most common form of dementia involving slowly developing, ultimately fatal neurodegeneration with massive brain atrophy especially in the medial temporal lobe, including the hippocampus (Hardy, 2006; Haass and Selkoe, 2007; Wang et al., 2007). AD is pathologically characterized by the presence of cerebral senile plaques containing extracellular deposits of $\beta$-amyloid peptide $(A \beta)$ from the amyloid precursor protein (APP), the accumulation of intraneuronal neurofibrillary tangles (NFTs) containing hyperphosphorylated tau protein, dysfunction of synapses, and loss of neurons (Mattson, 2004; Hardy, 2006).

In the 1990s, studies indicated that the most significant correlation to the severity of the cognitive impairment in $\mathrm{AD}$ was the loss of synapses in the frontal cortex and limbic system. Several years later, evidence supports the contention that neuronal cell death might occur later than the progression of neurodegeneration, and damage to the synapto-dendritic apparatus might be one of the earliest pathological alterations (Scheff and Price, 2003; Scheff et al., 2006). This is accompanied by the abnormal accumulation of $A \beta$ intraneuronally and extracellularly (e.g., plaques) or in intracellular compartments (e.g., tangles). Abnormal accumulation and misfolding (toxic conversion) of these synaptic and cytoskeletal proteins are being explored as key pathogenic events leading to neurodegeneration (Billings et al., 2005; McKee et al., 2008; Oakley et al., 2006).

We (Wang et al., 2010) and other group (Demars et al., 2010) recently identified that neurogenesis is compromised prior to any overt signs of AD-like pathology in a triple-transgenic mouse model of the disease. We propose that the neuronal loss in brain affected by $\mathrm{AD}$ may be due not only to the high death rate of neurons in affected brain regions, but also due to the reduced rate of the generation of new neurons. The reduction of generation of new neurons results in the limiting to replace the old, damaged, and dying neurons. In addition, the lower amount of new cells will further worsen the local micro-environment and will increase the speed of losing neurons (Wang et al., 2007, 2010). Therefore, the decrease of generation of new neurons may be the major causal factor.

Most AD is sporadic and the causal factors have not been clearly identified. Some complex interactions among different genetic variants and environmental factors are believed to modulate the risk for the vast majority of late-onset AD cases (McDonald et al., 2010). For example, the individuals carrying the $\varepsilon 4$ allele (a point mutation generated amino acid substitution from Cysteine to Arginine at position 158) of Apolipoprotein E (APOE) on chromosome 19 have an increased risk for developing sporadic AD. However, epidemiological studies indicate that the presence of the $A P O E$ $\varepsilon 4$ allele cannot explain the overall heritability of $\mathrm{AD}$, implying that a significant proportion of $\mathrm{AD}$ cases is attributable to additional genetic risk factors (Bickeboller et al., 1997; LaFerla et al., 1997). Recently identified polymorphism P86L in calcium homeostasis modulator 1 , which increases $A \beta$ levels by interfering with calcium homeostasis modulator 1-mediated $\mathrm{Ca}^{2+}$ permeability, is an example (Dreses-Werringloer et al., 2008; Marambaud et al., 2009). Although a detailed investigation to study the contribution of APOE $\varepsilon 4$ allele and CALHM1 P86L in a population who carrying both point mutations is still missing, combined evidence suggests that sustained disruption of intracellular $\mathrm{Ca}^{2+}$ signaling may play an early proximal and perhaps central role in $\mathrm{AD}$ pathogenesis (Smith et al., 2005; Gandy et al., 2006; Tu et al., 2006; Green and LaFerla, 2008). Interestingly, accumulated data indicated that transient increase of intracellular calcium concentration $\left(\left[\mathrm{Ca}^{2+}\right]_{\mathrm{i}}\right)$ may facilitate the neurogenesis (Dayanithi and Tapia-Arancibia, 1996; Wang and Brinton, 2008). These data suggest calcium homeostasis plays pivotal role on $\mathrm{AD}$ progression.

Numerous efforts have been made develop therapeutic strategies to delay or reverse the progression of neurodegenerative diseases, including $\mathrm{AD}$. Two recently published reviews have summarized the potential cellular targets for developing drugs to regulate the progression of neurodegenerative diseases (Aguzzi and Rajendran, 
2009; Rajendran et al., 2010). The current review specifically focuses on the potential targets involved in regulating the $\left[\mathrm{Ca}^{2+}\right]_{i}$ and subsequently mediated neurogenesis in neurodegenerative condition.

\section{TRANSIENT AND SUSTAINED CA ${ }^{2+}$ INCREASES}

$\mathrm{Ca}^{2+}$ is a ubiquitous second messenger that has been implicated in the regulation of a variety of events in developing neurons, including proliferation, migration, differentiation, and circuit formation (Gomez and Spitzer, 2000; Spitzer, 2008). Cells commence to divide by crossing from G1 to $S$ phase and initiating DNA amplification, a transition that is often environmentally regulated and associated with $\left[\mathrm{Ca}^{2+}\right]_{\mathrm{i}}$ transient increases (Spitzer et al., 1995; Spitzer, 2008). It have been reported that transient $\left[\mathrm{Ca}^{2+}\right]_{i}$ increases within the neural progenitor cells (NPC) is triggered by a neurosteroid, allopregnanolone, which is a $\mathrm{GABA}_{\mathrm{A}}$ receptor modulator, and is mediated by a voltage-gated calcium channel. In addition, contact-dependent signals and short-range diffusible factors such as neurotrophins may also influence $\left[\mathrm{Ca}^{2+}\right]_{i}$. Many growth factors, including bFGF, act via tyrosine kinase receptors that in turn can lead to release of $\mathrm{Ca}^{2+}$ from intracellular stores (Chao et al., 1992; Reddy, 1994; Berridge, 1995; Gomez-Lechon et al., 1996). Transient increases in $\left[\mathrm{Ca}^{2+}\right]_{\mathrm{i}}$ have been associated with the onset of cytokinesis and with the activation of actomyosin filaments that serve to separate daughter cells at the end of telophase (Ratan et al., 1988). The $\left[\mathrm{Ca}^{2+}\right]$ increases observed in doublets could be associated with these cell cycle events (Ratan et al., 1988). Both $\mathrm{Ca}^{2+}$ influx and release of $\mathrm{Ca}^{2+}$ from intracellular stores contribute to the $\left[\mathrm{Ca}^{2+}\right]_{\mathrm{i}}$ fluctuation associated with granule cell migration (Komuro and Rakic, 1996) and dendritic spine growth cone formation (Spitzer et al., 1995; Obrietan and van den Pol, 1996). All these data indicate that transient $\left[\mathrm{Ca}^{2+}\right]_{\mathrm{i}}$ increase enhances neurogenesis, from proliferation, migration and the growth of neurorites.

In addition to the effects on proliferation, the AP $\alpha$-induced transient increase of $\left[\mathrm{Ca}^{2+}\right]_{\mathrm{i}}$ also contributes to the release of oxytocin from supraoptic nucleus of those very young rats, but not old rats (Viero et al., 2006). Further study confirmed that neuroactive steroids on $\left[\mathrm{Ca}^{2+}\right]_{\mathrm{i}}$ transients is mediated by $\mathrm{GABA}_{\mathrm{A}}$ receptor activation and suggested an involvement of voltage-activated $\mathrm{Ca}^{2+}$ channels in cultured dorsal root ganglia neurons at embryonic stage E13 (Viero et al., 2006).

In contrast to the transient calcium increases which lead to the cell proliferation and neuropeptide release, sustained increases of $\left[\mathrm{Ca}^{2+}\right]_{\mathrm{i}}$ is a basic molecular mechanism for the increased sensitivity of cell response to toxicity and may eventually lead to cell death. For example, exposure of cultured PC12 cells to staurosporine, a broad spectrum protein kinase inhibitor, has been used to induce cell death in a wide range of cell types, resulted in prolonged (1-6h) elevation of $\left[\mathrm{Ca}^{2+}\right]_{\mathrm{i}}$ and cell apopotosis (Kruman et al., 1998; Seo and Seo, 2009). In many cell types, alteration of $\left[\mathrm{Ca}^{2+}\right]_{\mathrm{i}}$ plays a pivotal role in initiating apoptosis. Analysis of brain tissue from $\mathrm{AD}$ patient showed that a sustained $\left[\mathrm{Ca}^{2+}\right]_{\mathrm{i}}$ increase is associated with the neurofibrillary tangle-bearing neurons (Murray et al., 1992). In addition, $A \beta$ impaired the proliferation and neuronal differentiation of cultured human and rodent NPC, and promoted apoptosis of neuron-restricted NPC by a mechanism involving dysregulation of cellular calcium homeostasis and the activation of calpains and caspases (Haughey et al., 2002; Nimmrich et al., 2008).
Numerous findings have also suggested that perturbation of $\left[\mathrm{Ca}^{2+}\right]_{\mathrm{i}}$ signaling contributes to many age related neurodegenerative disorders, including: Parkinson's disease (PD), Huntington's disease (HD), ischemic stroke, and AD. Therefore, selective enhancement of the transient calcium increases may provide a promising strategy for developing anti-neurodegenerative diseases, neurogenic agents.

\section{NEUROGENESIS IN AD BRAIN}

It is well known that the rostral subventricular zone (SVZ) and the subgranular zone (SGZ) of the hippocampal dentate gyrus have the capacity of generating neurons into adulthood (Gage et al., 1998). Some studies provide evidence for a disruption of NPC in an amyloidogenic environment and support findings that neurogenesis is differentially affected among various transgenic mouse models of $\mathrm{AD}$, probably due to variations in promoter cell type specificity, expression levels, and other factors. A more comprehensive analysis of neurogenesis in APP transgenic mice showed that while in the molecular layer of the dentate gyrus there is an increased number of NPC, in the SGZ, markers of neurogenesis are decreased, indicating that in APP animals there is altered migration and increased apoptosis of NPC that contributes to the deficits in neurogenesis (Donovan et al., 2006).

Indeed, during aging, there is an age-related decline of adult neurogenesis and this decline is mostly related to decreased proliferation, associated with decreased stimulation to proliferate in aging brains. In the mouse model of $\mathrm{AD}$, there is also evidence for decreased neurogenesis that accompanies the neuronal loss characteristic of the disease (Rao et al., 2005). Studies from primates further demonstrate that there is a positive correlation between learning performance and the level of neurogenesis (Aizawa et al., 2009, 2011). Interestingly, studies of human brains and transgenic animal models have demonstrated significant alterations in the process of adult neurogenesis in the hippocampus in $\mathrm{AD}$ (Donovan et al., 2006). The decline of neurogenesis in the SGZ of the dentate gyrus of different transgenic mouse of $\mathrm{AD}$ have been consistently reported with an decrease of the numbers of bromodeoxyuridine, Ki-67, and doublecortin positive cells (Haughey et al., 2002; Dong et al., 2004; Wen et al., 2004; Rockenstein et al., 2007; Zhang et al., 2007; Rodriguez et al., 2008; Wang et al., 2010). One important finding common to several of these APP transgenic models is that there is no obvious neuronal dropout in the early stages of pathogenesis (Dickson, 2004). In fact, the earliest neuronal pathology before amyloid deposition is the neurogenic deficits in SGZ in hippocampus and SVZ of cerebral cortex (Demars et al., 2010; Wang et al., 2010). These are accompanied by and cognitive deficits in learning and memory (Wang et al., 2010). All these data suggest that the reduction of generation of new neurons might be a major causal factor for eventually a less number of neurons observed in brain affected by AD. Therefore, attenuation the neurogenic decline in subjects potentially suffered by $\mathrm{AD}$ may help Alzheimer's patients significantly.

\section{STRATEGY TO INCREASE HIPPOCAMPAL NEUROGENESIS IN AD}

These above findings open prospects for new strategies that can increase neurogenesis in normal or pathological processes in the aging brain of $\mathrm{AD}$, and hence decrease memory deficits. The first strategy is exogenous delivery of neural stem cells into the affected 
brain. Studies using this strategy were less successful due to the complexity of brain region delivery, difficulty of survival, migration, differentiation, and integration of the exogenous cells in an already demolished brain, as well as the complexity from immune rejection and ethics issues. To overcome these limitations, the promotion of the proliferation of neural stem cells within the brain is crucial. Moreover, a successful promotion of the endogenous neurogenesis will also improve the local brain microenviroment to a condition which is suitable for generation and survival of new cells (Wang et al., 2007).

Multiple analyses have documented that dentate neurogenesis is regulated by fibroblast growth factor 2 (FGF-2), insulin-like growth factor 1 (IGF-1) and vascular endothelial growth factor (VEGF) (Shetty et al., 2005). While the mechanism of age-associated decline in neurogenesis remains to be fully determined, loss in growth factors, FGF-2, IGF-1, and VEGF, in the microenvironment of the SGZ is a prime contributor to the reduced neurogenic potential of SGZ (Zhang et al., 2003; Wang et al., 2008c). Some results suggest that the dramatic decline in dentate neurogenesis observed as early as middle age could be linked to reduced concentrations of FGF-2, IGF-1, and VEGF in the hippocampus, as each of these factors can individually influence the proliferation of stem/progenitor cells in the SGZ of the dentate gyrus (Rao et al., 2005).

Thus, several growth factors have been investigated for promotion of neurogenesis in different AD models. Although this a one step further than the direct implant of exogenous neural stem cells into brain, one of the major challenges of this approach is the delivery of peptide growth factors to the brain. Large molecular weight growth factors do not readily cross the blood brain barrier and thus require direct infusion into the brain via acute or chronic indwelling catheters in the brain.

In contrast, small lipophilic molecules that penetrate the blood brain barrier and which induce a controlled targeted proliferation of neural stem or progenitor cells are promising therapeutic strategies (Brinton and Wang, 2006; Wang et al., 2008b). According to the definition of "neuroactive steroids," they include all steroids which are active on neural tissue whether or not they are synthesized locally. Besides their classical genomic effects, neuroactive steroids can affect neural tissue through a rapid non-genomic effect involving direct binding to the $\mathrm{GABA}_{\mathrm{A}}$ receptor (Belelli and Lambert, 2005).

Studies over the past two decades has demonstrated that the neurosteroid allopregnanolone (AP $\alpha ; 3 \alpha$-hydroxy- $5 \alpha$-hydroxy-pregnan20-one; also known as tetrahydroprogesterone; progesterone's primary metabolite) is a potent and stereoisomer specific allosteric modulator of the GABA chloride channel complex to increase conductance through the channel which can be protective against seizure activity (Brinton, 1994). Moreover, AP $\alpha$ can induce neurite regression of hippocampal neurons in culture (Brinton, 1994). Some results indicated that $\mathrm{AP} \alpha$ is a potent, stereoisomer specific promoter of neurogenesis of both rat hippocampal NPC and human cortical neural stem cells. AP $\alpha$ induced neurogenesis ranged from 20 to $30 \%$ in the rodent NPC to $37-49 \%$ in the human neural stem cells (Wang et al., 2005).

Our study demonstrated that $\mathrm{AP} \alpha$ not only increases proliferation of NPC of SGZ, but also increases neural progenitor cell proliferation in SVZ in triple transgenic mouse model for $\mathrm{AD}$ to the levels similar to that in the age and gender matched nontransgenic control mice (Wang et al., 2007, 2010). In addition, there is no significant effect on neural progenitor cell proliferation has been observed in non-transgenic control mice (Chen et al., 2009; Wang et al., 2010). These results indicated that $\mathrm{AP} \alpha$ only reverses the neurogenic deficits in brain of mice carrying human familial AD mutations, which have been consistently observed by different groups (Haughey et al., 2002; Dong et al., 2004; Wen et al., 2004; Zhang et al., 2007; Rodriguez et al., 2008).

$\mathrm{AP} \alpha$ increased expression of genes that promote transition through the cell cycle and proliferation, such as cyclins and CDKs including cell division control protein 2 (CDC2), cyclin B and proliferating cell nuclear antigen (PCNA) (Wang et al., 2005). AP $\alpha$ not only regulated the expression of cell cycle proteins and DNA amplification but also drove a complete mitosis of the rodent NPC (Wang et al., 2005). AP $\alpha$ is a metabolite of progesterone and a $\mathrm{GABA}_{\mathrm{A}}$ receptors modulator. It is now well established that the neurotransmitter GABA is excitatory at the embryonic stage. This excitatory action could play a trophic role promoting synapse formation (Ben-Ari, 2002). It appears that GABA signaling is essential during neural development and proliferation, particularly when interacting with neurosteroids (Gago et al., 2004). GABA receptor is an ion channel that allows either influx or efflux of chloride ions $\left(\mathrm{Cl}^{-}\right)$, depending upon the prevailing transmembrane $\left[\mathrm{Cl}^{-}\right]$ gradient. In mature neurons, AP $\alpha$ can bind to a specific site within the $\mathrm{GABA}_{\mathrm{A}}$ receptor at physiological concentrations $(6-35 \mathrm{nM})$ (Ben-Ari et al., 2007; Wang et al., 2008a) to increase chloride influx, thereby hyperpolarizing the neuronal membrane potential, and decreasing neuron excitability (Belelli et al., 2006). Because of the high intracellular chloride content in immature neurons, AP $\alpha$ provokes an efflux of chloride currents by the binding of GABAagonists to the $\mathrm{GABA}_{\mathrm{A}}$ receptors, depolarization of the membrane, opening the threshold of voltage-activated sodium channels and voltage activated calcium channels. The resulting $\mathrm{Na}^{+}$and $\mathrm{Ca}^{2+}$ currents in turn activate high-voltage activated calcium channels. This sequence of events is illustrated by experiments using inhibition by TTX and $\mathrm{Ni}^{2+} / \mathrm{Cd}^{2+}$ (action potentials blocker). AP $\alpha$ affects the $\mathrm{GABA}_{\mathrm{A}}$-induced $\left[\mathrm{Ca}^{2+}\right]_{\mathrm{i}}$ transients in a rapid and non-genomic manner (Wang and Brinton, 2008).

Recent analyses by Hosie et al. (2006) indicate that AP $\alpha$ can bind to two sites on the $\mathrm{GABA}_{\mathrm{A}}$ receptor, one that potentiates, and one that directly activates the $\mathrm{GABA}_{\mathrm{A}}$ receptor. The potentiating binding site of $\mathrm{AP} \alpha$ resides in a cavity formed by the $\alpha$-subunit transmembrane domains. The direct activating binding site of AP $\alpha$ located among interfacial residues between $\alpha$ and $\beta$ subunits and is enhanced by steroid binding to the potentiation site (Hosie et al., 2006). Data presented demonstrate that the AP $\alpha$-induced $\left[\mathrm{Ca}^{2+}\right]$ i rise can be abolished by two GABA ${ }_{\mathrm{A}}$ receptor blockers, namely bicuculline and picrotoxin (Wang and Brinton, 2008), strongly supporting the notion that the AP $\alpha$-induced $\left[\mathrm{Ca}^{2+}\right]_{\mathrm{i}}$ rise is a $\mathrm{GABA}_{\mathrm{A}}$ receptor-mediated process and most likely through the direct activating binding site.

Interestingly, cultured hippocampal neurons respond $\mathrm{AP} \alpha$ with high, low magnitudes and some has no response (Wang and Brinton, 2008). Given that the culture is a mixture of different developing stage of neuronal cells, these differential responses on $\left[\mathrm{Ca}^{2+}\right]_{i}$ to AP $\alpha$ exposure, most likely, reflect the heterogeneity of the $\mathrm{GABA}_{\mathrm{A}}$ 
receptor. Although heterogeneity of the subunit combination exists, all studies suggest that the effects of AP $\alpha$ depend on subunit combinations of the $\mathrm{GABA}_{\mathrm{A}}$ receptor and the combination is changing during development. Therefore, the different $\mathrm{GABA}_{\mathrm{A}}$ receptor subunit combinations might be the underlying mechanism for the variety of $A P \alpha$-induced $\left[\mathrm{Ca}^{2+}\right]_{\mathrm{i}}$ responses in cultured hippocampal neurons (Wang and Brinton, 2008).

The AP $\alpha$ treatment, not only reversed the neurogenesis deficits, it also reversed the cognitive deficits of the $3 \times \operatorname{TgAD}$ mice (Wang et al., 2007, 2010). The potential mechanism of AP $\alpha$ action is likely mediated by transient $\left[\mathrm{Ca}^{2+}\right]_{\mathrm{i}}$ increase (Dayanithi and TapiaArancibia, 1996; Wang and Brinton, 2008). It is well documented that calcium plays important roles in variety of neuronal functions and indirect evidence suggests that it may be involved in synaptic plasticity and in the regulation of gene expression correlated to long-term memory formation. As reported recently by Perisse et al. (2009), during olfactory conditioning $\mathrm{Ca}^{2+}$ is both a necessary and a sufficient signal for the formation of protein-dependent

\section{REFERENCES}

Aguzzi, A., and Rajendran, L. (2009). The transcellular spread of cytosolic amyloids, prions, and prionoids. Neuron 64, 783-790.

Aizawa, K., Ageyama, N., Yokoyama, C., and Hisatsune, T. (2009). Agedependent alteration in hippocampal neurogenesis correlates with learning performance of macaque monkeys. Exp. Anim. 58, 403-407.

Aizawa, K., Ageyama, N., Terao, K., and Hisatsune, T. (2011). Primate-specific alterations in neural stem/progenitor cells in the aged hippocampus. Neurobiol. Aging. 32, 140-150.

Belelli, D., Herd, M. B., Mitchell, E. A., Peden, D. R., Vardy, A. W., Gentet, L., and Lambert, J. J. (2006). Neuroactive steroids and inhibitory neurotransmission: mechanisms of action and physiological relevance. Neuroscience 138, 821-829.

Belelli, D., and Lambert, J. J. (2005). Neurosteroids: endogenous regulators of the GABA(A) receptor. Nat. Rev. Neurosci. 6, 565-575.

Ben-Ari, Y. (2002). Excitatory actions of gaba during development: the nature of the nurture. Nat. Rev. Neurosci. 3 , 728-739.

Ben-Ari, Y., Gaiarsa, J. L., Tyzio, R., and Khazipov, R. (2007). GABA: a pioneer transmitter that excites immature neurons and generates primitive oscillations. Physiol. Rev. 87, 1215-1284.

Berridge, M. J. (1995). Calcium signalling and cell proliferation. Bioessays $17,491-500$

Bickeboller, H., Campion, D., Brice, A., Amouyel, P., Hannequin, D., Didierjean, O., Penet, C., Martin, C., Perez-Tur, J., Michon, A., Dubois, B., Ledoze, F., Thomas-Anterion, C.,
Pasquier, F., Puel, M., Demonet, J.F., Moreaud, O., Babron, M.C., Meulien, D., Guez, D., Chartier-Harlin, M.C., Frebourg, T., Agid, Y., Martinez, M., and Clerget-Darpoux, F. (1997). Apolipoprotein E and Alzheimer disease: genotype-specific risks by age and sex. Am. J. Hum. Genet. 60, 439-446.

Billings, L. M., Oddo, S., Green, K. N., McGaugh, J. L., and LaFerla, F. M. (2005). Intraneuronal Abeta causes the onset of early Alzheimer's disease-related cognitive deficits in transgenic mice. Neuron 45, 675-688.

Brinton, R. D. (1994). The neurosteroid 3 alpha-hydroxy- 5 alpha-pregnan-20 -one induces cytoarchitectural regression in cultured fetal hippocampal neurons. J. Neurosci. 14.

Brinton, R. D., and Wang, J. M. (2006). Preclinical analyses of the therapeutic potential of allopregnanolone to promote neurogenesis in vitro and in vivo in transgenic mouse model of Alzheimer's disease. Curr. Alzheimer Res. 3, 11-17.

Chao, T. S., Byron, K. L., Lee, K. M., Villereal,M., and Rosner, M. R. (1992). Activation of MAP kinases by calciumdependent and calcium-independent pathways. Stimulation by thapsigargin and epidermal growth factor. J. Biol.

Chen, S., Wang, J., Irwin, R. W., Yao, J., Liu, L., Hamilton, R. T., Lemus, J., and Brinton, R.D. (2009). Allopregnanolone Promotes Myelin Formation Associated with Decreased Accumulation of Amyloid $\beta$ in the Triple Transgenic Mouse Model of Alzheimer's Disease. Program No. 543.2. Neuroscience Meeting Planner. Chicago, IL: Society for Neuroscience [online]. Chem. 267, 19876-19883.

long-term memory. An earlier study also indicated that the spatial memory-related increase of protein kinase $\mathrm{C}$ isoforms in hippocampal cells is calcium dependent (Colombo et al., 1997; Colombo and Gallagher, 2002). Interestingly, mice carrying the mutated human APP showed lower memory, impaired neuogenesis, and dysregulated cellular calcium homeostasis in hippocampal NPC (Haughey et al., 2002). These studies support our proposal, that maintaining a healthy calcium homeostasis in NPC by AP $\alpha$ may be a key for anti-AD and other neurodegenerative diseases.

Taken together, we propose that the AP $\alpha$-induced $\left[\mathrm{Ca}^{2+}\right]_{\mathrm{i}}$ transient rise, regulated by the L-type calcium channel and evoked by $\mathrm{GABA}_{\mathrm{A}}$ receptor, may be the signaling initiation mechanism for $\mathrm{AP} \alpha$-induced neuroprogenitor proliferation and cell cycle gene expression. However, $\left[\mathrm{Ca}^{2+}\right]_{\mathrm{i}}$ sustained rise-induced by $A \beta$ oligomers may lead to $A \beta$ formation and deposition, and eventually a calcium regulated cell death. Conformational studies using AP $\alpha$ to switch the $A \beta$-induced sustained calcium increase to a transient calcium alteration is on progress.

Colombo, P. J., and Gallagher, M. (2002). Individual differences in spatial memory among aged rats are related to hippocampal PKCgamma immunoreactivity. Hippocampus 12, 285-289.

Colombo,P.J., Wetsel,W.C., and Gallagher, M. (1997). Spatial memory is related to hippocampal subcellular concentrations of calcium-dependent protein kinase $\mathrm{C}$ isoforms in young and aged rats. Proc. Natl. Acad. Sci. U.S.A. 94, 14195-14199.

Dayanithi, G., and Tapia-Arancibia, L. (1996). Rise in intracellular calcium viaa nongenomic effect of allopregnanolone in fetal rat hypothalamic neurons. J. Neurosci. 16, 130-136.

Demars, M., Hu, Y. S., Gadadhar, A., and Lazarov, O. (2010). Impaired neurogenesis is an early event in the etiology of familial Alzheimer's disease in transgenic mice. J. Neurosci. Res. 88, 2103-2117.

Dickson, D. W. (2004). Building a more perfect beast: APP transgenic mice with neuronal loss. Am. J. Pathol. 164, 1143-1146.

Dong, H., Goico, B., Martin, M., Csernansky, C.A., Bertchume, A., and Csernansky, J. G. (2004). Modulation of hippocampal cell proliferation, memory, and amyloid plaque deposition in APPsw (Tg2576) mutant mice by isolation stress. Neuroscience 127, 601-609.

Donovan, M. H., Yazdani, U., Norris, R. D., Games, D., German, D. C., and Eisch, A. J. (2006). Decreased adult hippocampal neurogenesis in the PDAPP mouse model of Alzheimer's disease. J. Comp. Neurol. 495, 70-83.

Dreses-Werringloer, U., Lambert, J. C., Vingtdeux, V., Zhao, H., Vais, H., Siebert, A., Jain, A., Koppel, J., RoveletLecrux, A., Hannequin, D., Pasquier,
F., Galimberti, D., Scarpini, E., Mann, D., Lendon, C. Campion, D., Amouyel, P., Davies, P., Foskett, J. K., Campagne, F., and Marambaud, P. (2008). A polymorphism in CALHM1 influences $\mathrm{Ca} 2+$ homeostasis, Abeta levels, and Alzheimer's disease risk. Cell 133, 1149-1161.

Gage, F. H., Kempermann, G., Palmer, T. D., Peterson, D. A., and Ray, J. (1998). Multipotent progenitor cells in the adult dentate gyrus. J. Neurobiol. 36, 249-266.

Gago, N., El-Etr, M., Sananes, N., Cadepond, F., Samuel, D., AvellanaAdalid, V., Baron-Van Evercooren, A., and Schumacher, M. (2004). 3alpha,5alpha-Tetrahydroprogesterone (allopregnanolone) and gamma-aminobutyric acid: autocrine/ paracrine interactions in the control of neonatal PSA-NCAM+ proliferation. J. Neurosci. Res. 78, 770-783.

Gandy, S., Doeven, M. K., and Poolman, B. (2006). Alzheimer disease: presenilin springs a leak. Nat. Med. 12, 1121-1123.

Gomez-Lechon, M. J., Guillen, I., Ponsoda, X., Fabra, R., Trullenque, R., Nakamura, T., and Castell, J. V. (1996). Cell cycle progression proteins (cyclins), oncogene expression, and signal transduction during the proliferative response of human hepatocytes to hepatocyte growth factor. Hepatology 23, 1012-1019.

Gomez, T. M., and Spitzer, N. C. (2000). Regulation of growth cone behavior by calcium: new dynamics to earlier perspectives. J. Neurobiol. 44, 174-183.

Green, K. N., and LaFerla, F. M. (2008). Linking calcium to Abeta and Alzheimer's disease. Neuron 59, 190-194. 
Haass, C., and Selkoe, D. J. (2007). Soluble protein oligomers in neurodegeneration: lessons from the Alzheimer's amyloid beta-peptide. Nat. Rev. Mol. Cell Biol. 8, 101-112.

Hardy, J. (2006). A hundred years of Alzheimer's disease research. Neuron $52,3-13$.

Haughey, N. J., Nath, A., Chan, S. L., Borchard, A. C., Rao, M. S., and Mattson, M. P. (2002). Disruption of neurogenesis by amyloid betapeptide, and perturbed neural progenitor cell homeostasis, in models of Alzheimer's disease. J. Neurochem. 83, 1509-1524.

Hosie, A. M., Wilkins, M. E., da Silva, H. M., and Smart, T. G. (2006). Endogenous neurosteroids regulate GABAA receptors through two discrete transmembrane sites. Nature 444, 486-489.

Komuro, H., and Rakic, P. (1996). Intracellular Ca2+ fluctuations modulate the rate of neuronal migration. Neuron 17, 275-285.

Kruman, I., Guo, Q., and Mattson, M. P. (1998). Calcium and reactive oxygen species mediate staurosporineinduced mitochondrial dysfunction and apoptosis in PC12 cells. J. Neurosci. Res. 51, 293-308.

LaFerla, F. M., Troncoso, J. C., Strickland, D. K., Kawas, C. H., and Jay, G. (1997). Neuronal cell death in Alzheimer's disease correlates with apoE uptake and intracellular Abeta stabilization. J. Clin. Invest. 100, 310-320.

Marambaud, P., Dreses-Werringloer, U., and Vingtdeux, V. (2009). Calcium signaling in neurodegeneration. Mol. Neurodegener. 4, 20.

Mattson, M. P. (2004). Pathways towards and away from Alzheimer's disease. Nature 430, 631-639.

McDonald, R. J., Craig, L. A., and Hong, N. S. (2010). The etiology of age-related dementia is more complicated than we think. Behav. Brain Res. 214, 3-11.

McKee, A. C., Carreras, I., Hossain, L., Ryu, H., Klein, W. L., Oddo, S., LaFerla, F. M., Jenkins, B. G., Kowall, N. W., and Dedeoglu, A. (2008). Ibuprofen reduces Abeta, hyperphosphorylated tau and memory deficits in Alzheimer mice. Brain Res. 1207, 225-236.

Murray, F. E., Landsberg, J. P., Williams, R. J., Esiri, M. M., and Watt, F. (1992). Elemental analysis of neurofibrillary tangles in Alzheimer's disease using proton-induced X-ray analysis. Ciba Found. Symp. 169, 201-210; discussion 210-206.

Nimmrich, V., Grimm, C., Draguhn, A., Barghorn, S., Lehmann, A.,
Schoemaker, H., Hillen, H., Gross, G., Ebert, U., and Bruehl, C. (2008). Amyloid beta oligomers (A beta(1-42) globulomer) suppress spontaneous synaptic activity by inhibition of P/Qtype calcium currents. J. Neurosci. 28, 788-797.

Oakley, H., Cole, S. L., Logan, S., Maus, E., Shao, P., Craft, J., GuillozetBongaarts, A., Ohno, M., Disterhoft, J., Van Eldik, L., Berry, R., and Vassar, R. (2006). Intraneuronal beta-amyloid aggregates, neurodegeneration, and neuron loss in transgenic mice with five familial Alzheimer's disease mutations: potential factors in amyloid plaque formation. J. Neurosci. 26, 10129-10140.

Obrietan, K., and van den Pol, A. N. (1996). Growth cone calcium elevation by GABA. J. Comp. Neurol. 372, 167-175.

Perisse, E., Raymond-Delpech, V., Neant, I., Matsumoto, Y., Leclerc, C., Moreau, M., and Sandoz, J. C. (2009). Early calcium increase triggers the formation of olfactory long-term memory in honeybees. BMC Biol. 7, 30. doi: 10.1186/1741-7007-7-30.

Rajendran, L., Knolker, H. J., and Simons, K. (2010). Subcellular targeting strategies for drug design and delivery. Nat. Rev. Drug Discov. 9, 29-42.

Rao, M. S., Hattiangady, B., AbdelRahman, A., Stanley, D. P., and Shetty, A. K. (2005). Newly born cells in the ageing dentate gyrus display normal migration, survival and neuronal fate choice but endure retarded early maturation. Eur. J. Neurosci. 21, 464-476.

Ratan, R. R., Maxfield, F. R., and Shelanski, M. L. (1988). Long-lasting and rapid calcium changes during mitosis. J. Cell Biol. 107, 993-999.

Reddy, G. P. (1994). Cell cycle: regulatory events in $\mathrm{G} 1 \rightarrow \mathrm{S}$ transition of mammalian cells. J. Cell. Biochem. 54, 379-386.

Rockenstein, E., Crews, L., and Masliah, E (2007). Transgenic animal models of neurodegenerative diseases and their application to treatment development. Adv. Drug Deliv. Rev. 59, 1093-1102.

Rodriguez, J. J., Jones, V. C., Tabuchi, M., Allan, S. M., Knight, E. M., LaFerla, F. M., Oddo, S., and Verkhratsky, A. (2008). Impaired adult neurogenesis in the dentate gyrus of a triple transgenic mouse model of Alzheimer's disease. PLoS ONE3, e2935. doi: 10.1371/ journal.pone.0002935.

Scheff, S. W., and Price, D. A. (2003). Synaptic pathology in Alzheimer's disease: a review of ultrastructural studies. Neurobiol. Aging 24, 1029-1046.
Scheff, S. W., Price, D. A., Schmitt, F. A. and Mufson, E. J. (2006). Hippocampal synaptic loss in early Alzheimer's disease and mild cognitive impairment. Neurobiol. Aging 27, 1372-1384.

Seo, S. R., and Seo, J. T. (2009). Calcium overload is essential for the acceleration of staurosporine-induced cell death following neuronal differentiation in PC12 cells. Exp. Mol. Med. 41, 269-276.

Shetty, A. K., Hattiangady, B., and Shetty, G.A. (2005). Stem/progenitor cell proliferation factors FGF-2, IGF-1, and VEGF exhibit early decline during the course of aging in the hippocampus: role of astrocytes. Glia. 51, 173-186.

Smith, I. F., Green, K. N., and LaFerla, F. M. (2005). Calcium dysregulation in Alzheimer's disease: recent advances gained from genetically modified animals. Cell Calcium 38, 427-437.

Spitzer, N. C. (2008). Calcium: first messenger. Nat. Neurosci. 11, 243-244.

Spitzer, N. C., Olson, E., and Gu, X. (1995). Spontaneous calcium transients regulate neuronal plasticity in developing neurons. J. Neurobiol. 26, 316-324.

Tu, H., Nelson, O., Bezprozvanny, A. Wang, Z., Lee, S. F., Hao, Y. H., Serneels, L., De Strooper, B., Yu, G., and Bezprozvanny, I. (2006). Presenilins form ER Ca2+ leak channels, a function disrupted by familial Alzheimer's disease-linked mutations. Cell 126, 981-993.

Viero, C., Mechaly, I., Aptel, H., Puech, S. Valmier, J., Bancel, F., and Dayanithi, G. (2006). Rapid inhibition of Ca2+ influx by neurosteroids in murine embryonic sensory neurones. Cell Calcium 40, 383-391.

Wang, J. M., and Brinton, R. D. (2008) Allopregnanolone-induced rise in intracellular calcium in embryonic hippocampal neurons parallels their proliferative potential. BMCNeurosci. 9(Suppl. 2), S11. doi: 10.1186/14712202-9-S2-S11.

Wang, J. M., Irwin, R. W., Liu, L., Chen, S., and Brinton, R. D. (2007). Regeneration in a degenerating brain: potential of allopregnanolone as a neuroregenerative agent. Curr. Alzheimer Res. 4, 510-517.

Wang, J. M., Johnston, P. B., Ball, B. G. and Brinton, R. D. (2005). The neurosteroid allopregnanolone promotes proliferation of rodent and human neural progenitor cells and regulates cell-cycle gene and protein expression. J. Neurosci. 25, 4706-4718.

Wang, D.D., Kriegstein,A.R., and Ben-Ari, Y. (2008a). GABA regulates stem cell proliferation before nervous system formation. Epilepsy Curr. 8, 137-139.
Wang, J. M., Liu, L., Irwin, R. W., Chen, S., and Brinton, R. D. (2008b). Regenerative potential of allopregnanolone. Brain Res. Rev. 57, 398-409.

Wang, L., Chopp, M., Gregg, S. R., Zhang, R. L., Teng, H., Jiang, A., Feng, Y., and Zhang, Z. G. (2008c). Neural progenitor cells treated with EPO induce angiogenesis through the production of VEGF. J. Cereb. Blood Flow Metab. 28, 1361-1368.

Wang, J. M., Singh, C., Liu, L., Irwin, R. W., Chen, S., Chung, E. J., Thompson, R. F., and Brinton, R. D. (2010). Allopregnanolone reverses neurogenic and cognitive deficits in mouse model of Alzheimer's disease. Proc. Natl. Acad. Sci. U.S.A. 107, 6498-6503.

Wen, P. H., Hof, P. R., Chen, X., Gluck, K., Austin, G., Younkin, S. G., Younkin, L. H., DeGasperi, R., Gama Sosa, M. A., Robakis, N. K., Haroutunian, V., and Elder, G. A. (2004). The presenilin-1 familial Alzheimer disease mutant P117L impairs neurogenesis in the hippocampus of adult mice. Exp. Neurol. 188, 224-237.

Zhang, C., McNeil, E., Dressler, L., and Siman, R. (2007). Long-lasting impairment in hippocampal neurogenesis associated with amyloid deposition in a knock-in mouse model of familial Alzheimer's disease. Exp. Neurol. 204, 77-87.

Zhang, H., Vutskits, L., Pepper, M. S., and Kiss, J. Z. (2003). VEGF is a chemoattractant for FGF-2-stimulated neural progenitors. J. Cell Biol. 163, 1375-1384.

Conflict of Interest Statement: The authors declare that the research was conducted in the absence of any commercial or financial relationships that could be construed as a potential conflict of interest.

Received: 15 August 2010; paper pending published: 15 September 2010; accepted: 09 November 2010; published online: 02 December 2010.

Citation: Wang JM and Sun C (2010) Calcium and neurogenesis in Alzheimer's disease. Front. Neurosci. 4:194. doi: 10.3389/fnins.2010.00194

This article was submitted to Frontiers in Neuropharmacology, a specialty of Frontiers in Neuroscience.

Copyright (c) 2010 Wang and Sun. This is an open-access article subject to an exclusive license agreement between the authors and the Frontiers Research Foundation, which permits unrestricted use, distribution, and reproduction in any medium, provided the original authors and source are credited. 